\title{
On Predicting the Long Run Behaviour of Nigerian Bank Stocks Prices: a Markov Chain Approach
}

\author{
Christian Elendu Onwukwe, Timothy Kayode Samson* \\ Department of Mathematics/Statistics and Computer Science, University of Calabar, Cross River State, Nigeria \\ *Corresponding author: timstat@yahoo.com
}

Received May 29, 2014; Revised July 11, 2014; Accepted July 27, 2014

\begin{abstract}
This study examines the long run behaviour of the closing prices of the Nigerian bank stocks using Markov Chain. A total of eight (8) Nigerian bank stocks were randomly selected and data on their daily closing prices between 1st January, 2004 and 29th May, 2013 were collected secondarily through cashcrasft website. Then, variations in daily closing prices were classified into three states Markov Chain of drop, rise and stable. If the closing at day $t+1$ is greater than that of the day $t$, it was classified as rise, if that of the day $t+1$ is less than that of the day $t$, it was classified as drop but when the closing price for day $t$ is same as that of the day $t+1$, it was classified as stable. Based on these classifications, transition probabilities, the limiting distribution of the transition matrix as well as the steady state transition probabilities were computed for each stock. Finding suggests that despite the current situation in the market, there is still hope for Nigerian bank stocks as some of these bank stocks tend to experience an increase in price in the long run as shown by the results of the steady state probability. Although, this finding is very informative and crucial to investors, stock brokers and other regulator in this sector, this finding is subject to unforeseen circumstances such as change in government policy, among many other factors. Despite these limitations, it is hope that the results of this study will very useful to investors, intending investors and other relevant stakeholders who are involve in stock trading.
\end{abstract}

Keywords: Markov Chain, transition probability, steady state probability

Cite This Article: Christian Elendu Onwukwe, and Timothy Kayode Samson, "On Predicting the Long Run Behaviour of Nigerian Bank Stocks Prices: a Markov Chain Approach.” American Journal of Applied Mathematics and Statistics, vol. 2, no. 4 (2014): 212-215. doi: 10.12691/ajams-2-4-6.

\section{Introduction}

Investment in stock is essentially a long term investment and every investment carries its own risk. Stocks as form of investment in Nigeria just like any other countries of the world have suffered losses as a result of global economic meltdown (Olowe, 2009). This has resulted to loss of public confidence in Nigerian bank stocks especially bank stocks. Most of the investors do not even know whether there is hope for the Nigerian bank stocks as there has been a consistent downward trend in their closing prices. Although, scholars have come to agree that movement of stock prices is random and as such making the process to be unpredictable, nonetheless, Markov chain has proven to be relevant in the analysis of price movement. This is simply because Markov chain is a useful tool in making probabilistic statements about the future level of stock price (Eseoghene, 2011).

The Markov chain named after Andrey Markov, a Russian Mathematician is a mathematical system that undergoes transition from one state to another from a finite or countable number of possible states in a chain like manner. Markov chain can also be viewed as a random process endowed with the Markovian property which states that the next state depends only on the current state and not on the past. With the use of Markov chain, future behaviour can be predicted based on the observed behaviour of stocks over a period of time (Fielitz, 1969). Although predicting long run prospect of prices of stock have proven to be difficult because many factors such as political event, general economic conditions interact together in a disproportionate manner in influencing stock prices, nevertheless, studying the behaviour of these stocks in the long run is very crucial as it will help to predict the future behaviour of these stocks in the long run.

Similar study on the lung prospect of Nigerian bank stock has been conducted by Eseoghene (Eseoghene, 2011). He studied long run prospect of five Nigerian bank stocks using data collected between January 4th 2005June 30th 2008. But considering the effect of global economic crises which starting to be noticed in Nigeria in 2009, there is an urgent need to examine what is the current situation of these stocks with respect to their long run behaviour.

\section{Methodology}

Markov chain named after Andrey Markov is a sequence of random variables $X_{1}, X_{2}, X_{3}, \ldots ., X_{n}$ with the 
Markovian property

$\operatorname{Pr}\left(X_{n+1}=x / X_{1}=x_{1}, X_{2}=x_{2}, \ldots \ldots \ldots X_{n}=x_{n}\right)$

$=\operatorname{Pr}\left(X_{n+1}=x / X_{n}=x_{n}\right)$

The set of the possible values of $X_{i}$ are called the state space of the Markov chain. The transition probability of going from state $\mathrm{i}$ to $\mathrm{j}$ in $\mathrm{n}$ time step is

$P_{i j}^{(n)}=\operatorname{Pr}\left(X_{n}=j / X_{i-1}=i\right)$, and that of single step transition can be defined as

$$
P_{i j}=\operatorname{Pr}\left(X_{i}=j / X_{i-1}=i\right)
$$

Data were collected on daily closing price of eight (8) active Nigerian bank stocks between 1st Jan, 2004 to 29th May, 2013. Data were collected through secondary source through cashcraft website. Cash craft is one of the leading stocks broking firms in Nigeria and an active member of the Nigerian Stock Exchange. These data covered a period of above nine years. Variations in prices were classified as three state Markov Chain of rise(R), drop (D) and stable(S). If the closing price at day $t+1$ is greater than that of the day $\mathrm{t}$, we say there is a rise $\left(P_{t+1}>P_{t}\right)$, if $\left(P_{t+1}<P_{t}\right)$, it means there is a drop but if $\left(P_{t+1}=P_{t}\right)$ price is said to be stable. The numbers of rise- rise, risedrop, rise- stable, drop-rise, drop- drop, stable- stable were calculated and the results of the transition probability matrix are shown in Table 2. The computations of transition probability matrix are as shown below.

$$
\begin{aligned}
& P(R R)=\frac{n(R R)}{n(R R)+n(R D)+n(R S)}, \\
& P(R D)=\frac{n(R D)}{n(R R)+n(R D)+n(R S)}
\end{aligned}
$$

Since $P(R R)+P(R D)+P(R S)=1$, Then,

$$
\begin{gathered}
P(R S)=1-[P(R R)+P(R S)] \\
P(D R)=\frac{n(D R)}{n(D R)+n(D D)+n(D S)} \\
P(D D)=\frac{n(D D)}{n(D R)+n(D D)+n(D S)} \\
P(D S)=1-[P(D R)+P(D D)], \\
P(S R)=\frac{n(S R)}{n(S R)+n(S D)+n(S S)}, \\
P(S D)=\frac{n(S D)}{n(S R)+n(S D)+n(S S)} . \\
P(S S)=1-[P(S R)+P(S D)]
\end{gathered}
$$

Then, the transition probability matrix were then arranged as

$$
\left[\begin{array}{lll}
P(R R) & P(R D) & P(R S) \\
P(D R) & P(D D) & P(D S) \\
P(S R) & P(S D) & P(S S)
\end{array}\right]
$$

Where $P(R R)=$ Probability of price rising today and also rising tomorrow.
$P(R S)=$ Probability that stock prices remain stable after a previous rise.

$P(R D)=$ Probability that stock prices remain stable at the time $t+1$ after rising at time t (Previous day).

$P(S R)=$ Probability of stock price rising at the day $\mathrm{t}+1$ after being stable in the previous day.

$P(S S)=$ Probability that stock rise remains stable in the present day after remaining stable in previous day.

$P(S D)=$ Probability of dropping in present day after remaining stable in the preceding day.

$P(D R)=$ Probability that stock price rises after dropping in the previous today.

$P(D S)=$ Probability that stock prices remains stable after dropping in previous day.

$P(D D)=$ Probability that the stock price drop today after dropping the previous day.

$n(R S)=$ Number of stable at day $t+1$ and rise at the day t.

$n(R D)=$ Number of drop at day $t+1$ and rise at day $\mathrm{t}$.

$n(S R)=$ Number of rise at day $t+1$ and stable at day $\mathrm{t}$.

$n(S S)=$ Number of rise at day $t+1$ and rise at day $t$.

$n(S D)=$ Number of drop at day $t+1$ and stable at day $\mathrm{t}$.

$n(D R)=$ Number of rise at day $t+1$ and drop at day $t$.

$n(D S)=$ Number of rise at day $t+1$ and drop at day $\mathrm{t}$.

This long term or steady state probability will be $\left[R_{L}, S_{L}, D_{L}\right]$.

Where

$R_{L}$ will be probability of the stock rising in the long run.

$S_{L}$ is the probability of the stock being stable in the long run.

$D_{L}$ is the probability that the stock will drop in the long run.

Steady state probability $\lambda_{j}$ was computed using the formula

$$
\begin{gathered}
\lambda_{j}=\sum_{i \in S} \lambda_{i} p_{i j}, \mathrm{j}=1,2,3 \text { and } \mathrm{i}=1,2,3 \\
0 \leq \lambda_{j} \leq 1 \text { and } \sum \lambda_{j}=0 \\
p_{i j}=\left[\begin{array}{lll}
P(R R) & P(R D) & P(R S) \\
P(D R) & P(D D) & P(D S) \\
P(S R) & P(S D) & P(S S)
\end{array}\right]
\end{gathered}
$$

Evaluating equation 6, we have

$$
\begin{aligned}
& \lambda_{1}=\lambda_{1} P(R R)+\lambda_{2} P(D R)+\lambda_{3} P(S R), \\
& \lambda_{2}=\lambda_{1} P(R D)+\lambda_{2} P(D D)+\lambda_{3} P(D S), \\
& \lambda_{3}=\lambda_{1} P(R S)+\lambda_{2} P(D S)+\lambda_{3} P(S S)
\end{aligned}
$$

Collecting the like terms, we have

$$
\begin{aligned}
& \lambda_{1} P(R R)-\lambda+\lambda_{2} P(D R)+\lambda_{3} P(S R)=0, \\
& \lambda_{1} P(R D)+\lambda_{2} P(D D)-\lambda_{2}+\lambda_{3} P(D S)=0, \\
& \lambda_{1} P(R S)+\lambda_{2} P(D S)+\lambda_{3} P(S S)-\lambda_{3}=0 .
\end{aligned}
$$

Factorizing, we have 


$$
\begin{aligned}
& \lambda_{1}(P(R R)-1)+\lambda_{2} P(D R)+\lambda_{3} P(S R)=0, \\
& \lambda_{1} P(R D)+\lambda_{2}(P(D D)-1)+\lambda_{3} P(D S)=0, \\
& \lambda_{1} P(R S)+\lambda_{2} P(D S)+\lambda_{3}(P(S S)-1)=0 .
\end{aligned}
$$

The solution of the set of equations (9) gives the steady state probability $\lambda=\left(\lambda_{1}, \lambda_{2}, \lambda_{3}\right)$. Where, $0 \leq \lambda_{j} \leq 1$ and $\sum \lambda_{j}=0, \mathrm{j}=1,2,3$

The long term probability was computed as

$$
\lim _{n \rightarrow \infty} P^{n}
$$

These computations were facilitated using MS Excel, SPSS and MATLAB 7.5.0 (R2007b). To whether the closing prices are independent, the chi- square test was used. The Chi - Square test of independence is given by

$$
\chi^{2}=\sum \frac{\left(O_{i}-E_{i}\right)}{E_{i}}
$$

where, $O_{i}$ are the observed frequencies while $E_{i}$ are the expected frequencies.

\section{Results}

Table 1. $\chi^{2}$ Test of independence of the daily closing price

\begin{tabular}{ccc}
\hline Bank & $\chi^{2}$ & $\mathrm{p}$ - value \\
\hline Access & 1170.95 & $<0.001$ \\
GTB & 742.74 & $<0.001$ \\
Sky & 873.28 & $<0.001$ \\
FCMB & 742.95 & $<0.001$ \\
Zenith & 596.88 & $<0.001$ \\
UBN & 1535.23 & $<0.001$ \\
Wema & 1573.98 & $<0.001$ \\
Eco & 1427.23 & $<0.001$ \\
\hline
\end{tabular}

Results in Table 1 shows that the daily closing prices for all the eight bank stocks selected were not independent $(\mathrm{p}<0.05)$. This means that the daily closing prices depends on the subsequent daily closing prices. Table 2 provides the transition probability matrix (p) and long term

\begin{tabular}{|c|c|c|c|c|c|c|c|c|c|}
\hline \multirow{3}{*}{$\begin{array}{c}\text { Banks } \\
\text { Eco Bank }\end{array}$} & \multirow{2}{*}{\multicolumn{3}{|c|}{$\begin{array}{c}\text { Transition probability } \\
\mathrm{P}\end{array}$}} & \multirow{2}{*}{\multicolumn{3}{|c|}{$\begin{array}{l}\text { Long term probability matrix } \\
\qquad \lim _{n \rightarrow \infty} P^{n}\end{array}$}} & \multicolumn{3}{|c|}{ Steady state probability } \\
\hline & & & & & & & \multirow{2}{*}{$\begin{array}{c}\text { Rise }\left(\lambda_{1}\right) \\
0.1763\end{array}$} & \multirow{2}{*}{$\begin{array}{c}\operatorname{Low}\left(\lambda_{2}\right) \\
0.1959\end{array}$} & \multirow{2}{*}{$\begin{array}{c}\text { Stable }\left(\lambda_{3}\right) \\
0.6278\end{array}$} \\
\hline & $\begin{array}{l}0.5112 \\
0.3423 \\
0.0304\end{array}$ & $\begin{array}{l}0.3697 \\
0.4944 \\
0.0540\end{array}$ & $\left.\begin{array}{l}0.1191 \\
0.1633 \\
0.9156\end{array}\right)$ & $\begin{array}{l}0.1763 \\
0.1763 \\
0.1763\end{array}$ & $\begin{array}{l}0.1959 \\
0.1959 \\
0.1959\end{array}$ & $\left.\begin{array}{l}0.6278 \\
0.6278 \\
0.6278\end{array}\right)$ & & & \\
\hline FCMB & $\begin{array}{l}0.4964 \\
0.3866 \\
0.1116\end{array}$ & $\begin{array}{l}0.3791 \\
0.4771 \\
0.1697\end{array}$ & $\left.\begin{array}{l}0.1245 \\
0.1363 \\
0.7187\end{array}\right)$ & $\begin{array}{l}0.3364 \\
0.3364 \\
0.3364\end{array}$ & $\begin{array}{l}0.3467 \\
0.3467 \\
0.3467\end{array}$ & $\left.\begin{array}{l}0.3169 \\
0.3169 \\
0.3169\end{array}\right)$ & 0.3364 & 0.3467 & 0.3169 \\
\hline Zenith & $\left(\begin{array}{l}0.4920 \\
0.4281 \\
0.1821\end{array}\right.$ & $\begin{array}{l}0.4351 \\
0.4950 \\
0.2149\end{array}$ & $\left.\begin{array}{c}0.0729 \\
0.0769 \\
0.603\end{array}\right)$ & $\begin{array}{l}0.4156 \\
0.4156 \\
0.4156\end{array}$ & $\begin{array}{l}0.4256 \\
0.4256 \\
0.4256\end{array}$ & $\left.\begin{array}{l}0.1588 \\
0.1588 \\
0.1588\end{array}\right)$ & 0.4256 & 0.4156 & 0.1588 \\
\hline UBN & $\begin{array}{l}0.3772 \\
0.6172 \\
0.0220\end{array}$ & $\begin{array}{l}0.6048 \\
0.3722 \\
0.0440\end{array}$ & $\left.\begin{array}{c}0.018 \\
0.0106 \\
0.9340\end{array}\right)$ & $\begin{array}{l}0.4122 \\
0.4122 \\
0.4122\end{array}$ & $\begin{array}{l}0.4096 \\
0.4096 \\
0.4096\end{array}$ & $\left.\begin{array}{l}0.1782 \\
0.1782 \\
0.1782\end{array}\right)$ & 0.4122 & 0.4096 & 0.1782 \\
\hline GTB & $\begin{array}{l}0.5372 \\
0.4151 \\
0.1845\end{array}$ & $\begin{array}{l}0.4032 \\
0.5249 \\
0.2006\end{array}$ & $\left.\begin{array}{c}0.060 \\
0.060 \\
0.6149\end{array}\right)$ & $\begin{array}{l}0.4413 \\
0.4411 \\
0.4410\end{array}$ & $\begin{array}{l}0.4318 \\
0.4316 \\
0.4315\end{array}$ & $\left.\begin{array}{l}0.1360 \\
0.1359 \\
0.1359\end{array}\right)$ & 0.4413 & 0.4318 & 0.1360 \\
\hline Access & $\begin{array}{l}0.5374 \\
0.4109 \\
0.1095\end{array}$ & $\begin{array}{l}0.3980 \\
0.5124 \\
0.1131\end{array}$ & $\left.\begin{array}{l}0.0646 \\
0.0767 \\
0.7774\end{array}\right)$ & $\begin{array}{r}0.3874 \\
0.3874 \\
0.3874\end{array}$ & $\begin{array}{l}0.3720 \\
0.3720 \\
0.3720\end{array}$ & $\left.\begin{array}{l}0.2406 \\
0.2406 \\
0.2406\end{array}\right)$ & 0.3874 & 0.3720 & 0.2406 \\
\hline Sky & $\begin{array}{l}0.5337 \\
0.3889 \\
0.3462\end{array}$ & $\begin{array}{l}0.3890 \\
0.5244 \\
0.4780\end{array}$ & $\left.\begin{array}{l}0.0773 \\
0.0867 \\
0.1758\end{array}\right)$ & $\left(\begin{array}{l}0.4502 \\
0.4502 \\
0.4502\end{array}\right.$ & $\begin{array}{l}0.4592 \\
0.4592 \\
0.4592\end{array}$ & $\left.\begin{array}{l}0.0905 \\
0.0905 \\
0.0905\end{array}\right)$ & 0.4502 & 0.4592 & 0.0905 \\
\hline WEMA & $\left(\begin{array}{l}0.5772 \\
0.3329 \\
0.0419\end{array}\right.$ & $\begin{array}{l}0.3417 \\
0.5317 \\
0.0798\end{array}$ & $\left.\begin{array}{l}0.0811 \\
0.1354 \\
0.8783\end{array}\right)$ & $\left(\begin{array}{l}0.2588 \\
0.2588 \\
0.2588\end{array}\right.$ & $\begin{array}{l}0.2692 \\
0.2692 \\
0.2692\end{array}$ & $\left.\begin{array}{l}0.4720 \\
0.4720 \\
0.4720\end{array}\right)$ & 0.2588 & 0.2692 & 0.4720 \\
\hline
\end{tabular}
probability, matrix as well as steady state which give probability of stock increasing (rising), dropping and being stable for each of the selected bank stocks.

Table 2. The long Run Prospect of Nigerian Bank Stocks

Results in Table 2 shows that there is hope of recovering for Nigerian bank stocks after the experience of unprecedented loses in the years past. Banks like Zenith
Bank, Guaranty Trust Bank and Access Bank show a higher tendency of increase in price. For Eco Bank, probability of the stock to be stable in the long run is 
higher than that of rising and falling $(0.6278,0.1763$ and 0.1763 ) respectively. This is an indication that there is a high tendency for Eco bank stock to be stable in the long run. Similar results while obtained for Wema Bank. But for stocks like Union Bank and Sky Bank shows a higher likelihood of falling.

\section{Discussion of Findings}

The results of the analysis of long run behaviour of Nigerian bank stock shows that most these bank stocks have higher likelihood to increase in price (UBN, Access, Guaranty Trust Bank and Zenith bank), stock like Eco bank and WEMA shows a higher chances of being stable in the long run but stock like Union Bank and Skye Bank show a higher tendency of decrease in price in the long run. In summary, fifty percent of the stocks show a higher tendency of increase in price, twenty- five percent shows a higher likelihood of being stable and the remaining twenty- five percent show a higher likelihood of falling in the long run. The stability observed in some of these stocks is consistent with that of other similar studies conducted in Nigeria (Idolor, 2009, Esoghene, 2011).

Also, there are some disparities between the result of this present study and that of Eseoghene (2011) as some of the stocks show higher chances of increasing in price as against the former study which showed that most of the stocks will be stable in the long run. This disparity could be due to period when former study was conducted and also length of the data collected. This is because as at 2008, where the former study was conducted, Nigerian bank stocks have not experienced unprecedented loses as a result of the global economic meltdown as it is obtained of recent.

\section{Conclusion}

The study has examined the long run behaviour of Nigerian bank stocks. This study reveals that there is hope for Nigerian bank stocks as most of the stocks tend to record gain or remain stable in the long run. But this finding should be treated with caution as some other unforeseen circumstances like political events, economic condition and other changes in government policies may affect this finding.

\section{Reference}

[1] Eseoghene, I (2011). The long-run Prospect of stocks in the Nigerian Capital Market: A Markov Chain Analysis: JORIND (9): 388-400.

[2] Fielitz, B.D (1969). On the Behaviour of stock. Price Relatives as a Random Process with an Application to New York stock Exchange Prices: Unpublished Doctoral Dissertation, Kent State University, United State of America.

[3] Idolor, E.J (2009). The Behaviour of stock Process in the Nigerian Capital Market: A Markovian Analysis. Unpublished M. Sc Thesis, University of Benin, Nigeria.

[4] Olowe, R. A. (2009). Stock returns volatility and the global financial crisis in an emerging market: The Nigerian case. International Journal Research Review of Business Research Papers, 5 (4), 426-447.

[5] Website visited www.cashcraft.com 